\title{
The role of Vitom-3D in the management of spinal meningiomas: review of the literature and illustrative case
}

\author{
Oreste de Divitiis', Elena d'Avella', Matteo Sacco ${ }^{1}$, Teresa Somma', Mehmet Turgut ${ }^{2}$, Valentina Baro ${ }^{3}$, Luca \\ Denaro $^{3}$ \\ 'Department of Neurosurgery, Università degli Studi di Napoli "Federico II", Naples 80131, Italy. \\ ${ }^{2}$ Department of Neurosurgery, Adnan Menderes University School of Medicine, Aydın 09100, Turkey. \\ ${ }^{3}$ Department of Neurosurgery, University of Padua, Padua 35128, Italy.
}

Correspondence to: Dr. Elena d'Avella, Department of Neurosciences and Reproductive and Odontostomatological Sciences, Division of Neurosurgery, University of Napoli “Federico II", Via Pansini 5, Naples 80131, Italy. E-mail: elenadavella@gmail.com

\begin{abstract}
How to cite this article: de Divitiis O, d'Avella E, Sacco M, Somma T, Turgut M, Baro V, Denaro L. The role of Vitom-3D in the management of spinal meningiomas: review of the literature and illustrative case. Mini-invasive Surg 2020;4:75. http://dx.doi.org/10.20517/2574-1225.2020.66
\end{abstract}

Received: 30 Jun 2020 First Decision: 4 Sep 2020 Revised: 18 Sep 2020 Accepted: 24 Sep 2020 Published: 6 Nov 2020

Academic Editor: Giulio Belli Copy Editor: Cai-Hong Wang Production Editor: Jing Yu

\begin{abstract}
The favorable outcome generally associated with spinal meningioma surgery is the result of the continuing refinement of the surgical technique, the use of intraoperative neuromonitoring, and a better understanding of the tumor biological behavior. Among all the technological advancements, visualization tools are the keys to any successful surgical procedure. The operating microscope is the gold standard in all neurosurgical procedures. In recent years, high-definition exoscope systems have entered the field of neurosurgery, as another tool in the armamentarium of the contemporary neurosurgeon. After initial experiences and technical improvements, the exoscope has proven to be best suited for spinal procedures. This study aims to briefly review the exoscope journey in neurosurgery, with a special focus on spinal meningioma surgery. Benefits and limitations are analyzed and an illustrative case is reported. Spinal meningiomas removal under exoscope visualization has proven to be feasible, efficient, and safe. Indication for the use of the exoscope greatly depends on meningioma size, consistency, relationship to surrounding neurovascular structures, and the surgeon's experience. Switching to the operating microscope, if deemed safer, should always be considered.
\end{abstract}

Keywords: Ergonomics, exoscope, feasible, illumination, magnification, safe, teaching

\footnotetext{
(@) (

(C) The Author(s) 2020. Open Access This article is licensed under a Creative Commons Attribution 4.0 International License (https://creativecommons.org/licenses/by/4.0/), which permits unrestricted use, sharing, adaptation, distribution and reproduction in any medium or format, for any purpose, even commercially, as long as you give appropriate credit to the original author(s) and the source, provide a link to the Creative Commons license, and indicate if changes were made.
}

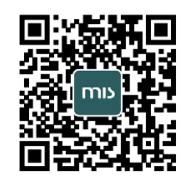




\section{INTRODUCTION}

Spinal meningiomas are intradural extra-medullary lesions that arise from meningothelial arachnoid cells within the spinal dura mater. They are the second most common intradural spine tumor, after neuromas, accounting for two-thirds of all intraspinal neoplasms. Surgical treatment of spinal meningiomas is associated with a favorable outcome, both in terms of progression-free survival rate and patients' neurological post-operative status. Improvements in spinal meningiomas surgery are the results of the continuing refinement of the surgical technique, the use of intraoperative neuromonitoring, and a better understanding of meningiomas biological behavior ${ }^{[1-4]}$. Spinal meningiomas have shown to be less likely to recur than their intracranial analogs, with the majority of series reporting no significant difference in recurrence rates between Simpson grade I and grade II resections ${ }^{[5]}$. The negligible oncological benefit of an aggressive surgical strategy that includes a wide removal of the dural attachment does not seem to outweigh the risk of surgical complications and patients' morbidity, especially for ventral and lateral spinal meningiomas. For this reason, there has been an attitude shift toward less aggressive resections, with the goal of minimizing morbidity ${ }^{[6-9]}$. The safety of meningiomas surgery is increased by the use of multimodal neuromonitoring: somatosensory-evoked potentials, motor evoked potentials, and D-waves provide the opportunity to assess the functional integrity of the spinal cord during surgery, bearing the risk of neurological complications. Therefore, intraoperative neuromonitoring adds to the modern treatment of spinal tumors and should be performed in spinal meningiomas surgery ${ }^{[10]}$.

Among all the technological advances, visualization, magnification, and the illumination of the surgical field are the keys to any successful surgical procedure. After few years from the introduction of the operating microscope by Yasargil and Krayenbuhl in the $1970 \mathrm{~s}^{[11]}$, Caspar demonstrated its usefulness for spinal surgery ${ }^{[12]}$ : the advent of the operating microscope in spinal procedures brought terrific improvement in terms of outcomes ${ }^{[13-16]}$. Since then, visualization tools have continued to evolve, along with the inexhaustible research of less invasive surgical techniques to address cranial and spinal pathologies. In the late 1990s, neurosurgeons began to use the endoscope, as a primary visualization tool or in assistance to the microscope. Neuroendoscopy found its best application in skull base approaches and intraventricular surgery ${ }^{[17-21]}$, while reports of endoscopic spinal surgery remain rather sparse in the literature ${ }^{[9]}$. In recent years, high-definition exoscope systems have entered the field of neurosurgery, as another tool in the armamentarium of the contemporary neurosurgeon ${ }^{[22]}$. Following preliminary convincing experiences with the exoscope and subsequent technical refinements, reports of application of this device in the setting of more complex cranial and spinal procedures have appeared in the literature ${ }^{[23-27]}$. Advantages and disadvantages of the exoscope over the well-established visualization tools, i.e., the operating microscope or endoscope, and the surgical settings in which it could be best indicated still need to be fully elucidated. This article aims to provide a cogent review of the exoscope journey in neurosurgery, with a special focus on spinal procedures and spinal meningioma surgery.

\section{EXOSCOPE IN NEUROSURGERY}

During the last three decades, telescopes have been recognized as a valid visualization tool in many surgical fields. The telescope optical system is attached to a high-quality television camera and the surgeon operates by visualizing the anatomic structures and instruments from a video monitor screen placed at an optimal distance. Typical telescopes have very short focal distances and must therefore be introduced directly into the body cavity. Because the lens sits within the body, these devices are usually referred to as endoscopes. Endoscopic visualization in neurosurgery finds its main indication for the treatment of intraventricular lesions and skull base surgery ${ }^{[17-19,28]}$. Exoscopes are telescope-based visualization tools that produce very high-quality video images with large focal distance and wide field of view. One of the advantages of the exoscope over the existing telescopes is that the exoscopes are positioned far away from the surgical field, at a distance of approximately 25 to $30 \mathrm{~cm}$. Distinctly from the endoscopic technique, exoscope facilitates the passage of instruments under the scope and does not require dedicated instrumentation. 
In 2008, Mamelak et al. ${ }^{[22]}$ reported the initial use of this novel tool in an animal model. The initial impression was that the exoscope had the potential for widespread application for human microsurgical procedures owing adequate image resolution, magnification, and easy and intuitive manipulation. Soon after the initial report, its clinical use has been tested in many surgical disciplines including vascular and cardiac surgery, ENT, hepatic surgery, and neurosurgery ${ }^{[23,26,29-34]}$. The outstanding quality of images was largely confirmed and the exoscope earned the right to be seen as another visualization tool in the armamentarium of the contemporary neurosurgeon. The first clinical series of patients undergoing surgery with the aim of the exoscope consisted of technically less demanding neurosurgical procedures for which it was felt that trial use of this device could not potentially affect surgical outcomes. That lack of 3D visualization was a concern to many surgeons and this drawback was mentioned frequently in preliminary studies ${ }^{[24,35-38]}$. It took about nine years to further evolve the $2 \mathrm{D}$ visualization and introduce the first $3 \mathrm{D}$ exoscopic visualization system ${ }^{[3,40]}$. In the following years, the $3 \mathrm{D}$ exoscope has been used to perform various technical more demanding neurosurgical procedures, even in pediatric cases, including treatment of cerebrovascular disorders (i.e., aneurysm clipping and bypass surgery), degenerative spinal disorders, and resection of cranial and spinal tumors ${ }^{[41-50]}$.

VITOM $^{\circledR}$-3D (Video Telescopic Operating Microscope, Karl Storz GmbH \& Co. KG, Tuttlingen, Germany), provides a $3 \mathrm{D}$ visualization in ultra-high definition $(4 \mathrm{~K})$ quality, with a focal length of $20-50 \mathrm{~mm}$ and magnification ranges from $8 \times$ to $30 \times$. It consists of four main parts: the VITOM ${ }^{\circ}-3 \mathrm{D}$ camera with integrated illuminator, the IMAGE 1 PILOT control unit, the IMAGE $1 \mathrm{~S}$ camera system, and the $3 \mathrm{D}$-monitor. The VITOM $^{\circ}-3 \mathrm{D}$ is fixed with a movable holding arm and the camera with an integrated illuminator is placed directly above the operation field at a distance of $25-30 \mathrm{~cm}$. The camera and control unit is connected to the IMAGE $1 \mathrm{~S}$ camera system. The 3D-monitor is placed about 1.5 to 2.0 meters distance in front of the surgeon. Ideally, the surgical team (surgeon, assistant, scrub nurse) can equally watch the surgical field on the $3 \mathrm{D}$-monitor by wearing polarized glasses.

The principle features of Vitom-3D allow working in a comfortable setting that is similar to endoscopic surgeries, with the optical advantages of the operating microscope [Figure 1].

The operating microscope is the gold-standard for visualization in neurosurgery ${ }^{[13,14,16]}$. However, it has several drawbacks: the cost, which might be up to 500.000 euros; the size, which might be a problem for the intraoperative set up in smaller operating theatres; the surgeon's posture that, depending on the personal height and the angle of the microscope at the surgical field, can result uncomfortable and affect the level of concentration in longer procedures. Finally, the monitor might not be always visible for the scrub nurse during intraoperative positioning. Offering the condition of visualizing the surgical field from a video monitor, both the exoscope and the endoscope require eyes-hands coordination that is different from the operating microscope. Looking and following more easily and immediately involve the operation on a screen, all the staff in the operating theater is more involved in the surgical work. Hence, the exoscope enables the trainees to benefit from a real-time step-by-step surgical learning experience.

The published literature reveals the increased interest in the application of exoscopic visualization in neurosurgery, with the vast majority of articles being published within the last two years ${ }^{[46,48,49,51-55]}$. Thanks to literature contributions, it became possible to analyze the advantages and limitations of Vitom-3D. Initial impressions were that the most obvious and clinically relevant benefits are related to working ergonomics (intuitive operating room setup, instrument handling, and surgeons' comfort) and trainees' learning experience. Some disadvantages such as headache, dizziness, and nausea due to wearing polarized glasses, the use of two monitors in selected cases were the surgeon and the assistant were positioned on the opposite side of the patient's body, and the inability to rotate the onscreen picture has been reported as well ${ }^{[39-41]}$. The main limitation of the Vitom-3D is the reduced illumination and magnification in the 


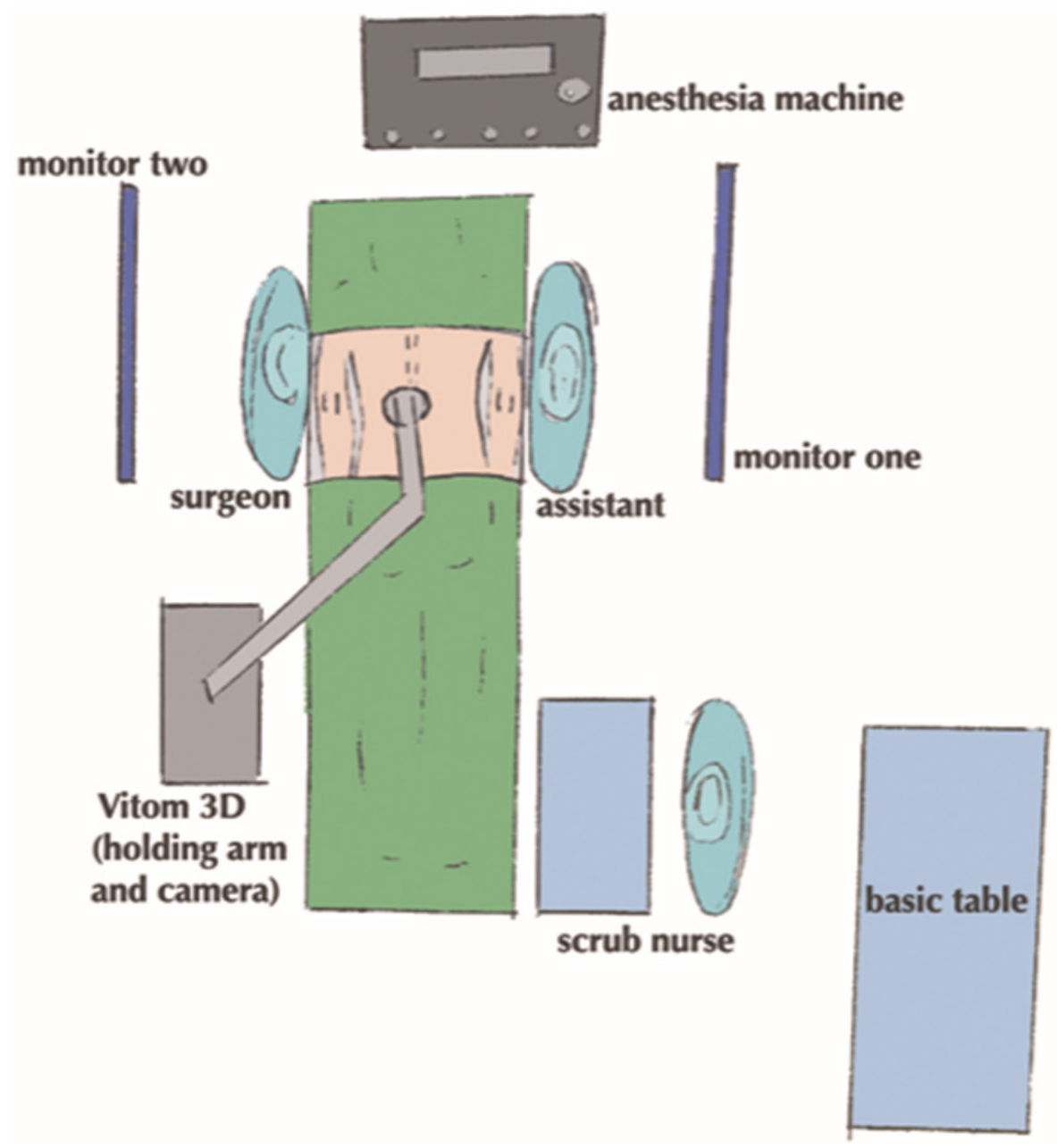

Figure 1. Schematic drawing showing the intra-operative set-up when spinal procedures are performed under Vitom-3D visualization

depth of the operative field compared to the operating microscope, especially with small dimensions of the approach. Once the surgeon feels that the procedure is becoming unsafe due to poor image quality, switching to the operating microscope may be required for better tissue identification and manipulation.

Vitom-3D is one of the exoscopic systems nowadays available for neurosurgical use ${ }^{[55]}$ [Table 1]. Each of these devices has its strengths and weaknesses, both from the ergonomic and optical point of view. The newer exoscopes can be upgraded combining other technological tools for surgical visualization and planning (navigation, white matter tractography, intra-operative green video angiography). The pros and cons of the different systems must be balanced, and their cost considered when choosing the ideal exoscope within a neurosurgical department.

\section{SPINAL MENINGIOMA SURGERY}

Along with the definition of advantages and disadvantages of the exoscope over the operating microscope or endoscope, the increased experience brought to light on the surgical setting in which the use of Vitom$3 \mathrm{D}$ could be best indicated. Table 2 summarizes the application of Vitom-3D to spinal procedures, both for degenerative diseases and tumors removal.

Among spinal pathologies, meningioma surgery probably epitomizes the indication for Vitom-3D application. The most frequently reported location for spinal meningiomas is the thoracic spine (67\%-84\%), 
Table 1. Main characteristics of exoscopic system options

\begin{tabular}{|c|c|c|c|c|c|}
\hline Exoscopic system & Optics & Ergonomics & Pros & Cons & Cost \\
\hline $\begin{array}{l}\text { Vitom } \\
\text { (Karl Storz, Tuttlingen, } \\
\text { Germany) }\end{array}$ & $\begin{array}{l}\text { Focal length: } 20-50 \mathrm{~mm} \\
\text { magnification: } 8 \times \text { to } 30 \times \\
3 D, H D, 4 K\end{array}$ & $\begin{array}{l}\text { The camera is mounted } \\
\text { on a fixed pneumatic } \\
\text { holder }\end{array}$ & $\begin{array}{l}\text { Extended working } \\
\text { distance }\end{array}$ & $\begin{array}{l}\text { Movements are } \\
\text { limited by the } \\
\text { holder }\end{array}$ & + \\
\hline $\begin{array}{l}\text { KINEVO } \\
\text { (Carl Zeiss AG, } \\
\text { Oberkochen, Germany) }\end{array}$ & $\begin{array}{l}\text { Focal length: } 200-625 \mathrm{~mm} \\
\text { magnification: } 10 \times \\
3 \mathrm{D}, \mathrm{HD}, 4 \mathrm{~K}\end{array}$ & $\begin{array}{l}\text { A robotic microscope that } \\
\text { can be converted into an } \\
\text { exoscope }\end{array}$ & $\begin{array}{l}\text { Integrated } \\
\text { navigation, ICG, } \\
\text { QEVO scope }\end{array}$ & $\begin{array}{l}\text { Heavy, } \\
\text { movements require } \\
2 \text { hands, } \\
\text { impaired workflow }\end{array}$ & ++++ \\
\hline $\begin{array}{l}\text { ORBEYE } \\
\text { (Olympus, Tokyo, Japan) }\end{array}$ & $\begin{array}{l}\text { Focal length: } 220-550 \mathrm{~mm} \\
\text { magnification: } 26 \times \\
3 \mathrm{D}, \mathrm{HD}, 4 \mathrm{~K}\end{array}$ & $\begin{array}{l}\text { Manual movement } \\
\text { utilizing a floor-based arm }\end{array}$ & Imaging quality & $\begin{array}{l}\text { Lack of integrating } \\
\text { software }\end{array}$ & ++ \\
\hline $\begin{array}{l}\text { Synaptive Modus V } \\
\text { (Synaptive Medical, } \\
\text { Toronto, Canada) }\end{array}$ & $\begin{array}{l}\text { Focal length: } 650 \mathrm{~mm} \\
\text { magnification: } 12.5 \times \\
2 \mathrm{D}, \mathrm{HD}\end{array}$ & $\begin{array}{l}\text { Manual movement } \\
\text { utilizing a floor-based arm }\end{array}$ & $\begin{array}{l}\text { Integrated } \\
\text { navigation and } \\
\text { tractography }\end{array}$ & Lack of 3D & +++ \\
\hline
\end{tabular}

Table 2. Review of the spinal procedures performed under exoscope visualization

\begin{tabular}{|c|c|c|c|c|c|}
\hline Author & Year & 2D/3D & Procedures & $\begin{array}{l}\text { Total No. } \\
\text { patients }\end{array}$ & Main findings \\
\hline Mamelak et al. ${ }^{[23]}$ & 2010 & $2 \mathrm{D}$ & $\begin{array}{l}\text { - } 2 \text { ACDF procedures } \\
\text { - } 2 \text { lumbar microdiskectomy } \\
\text { - } 1 \text { lumbar foraminotomy }\end{array}$ & 5 & $\begin{array}{l}\text { - Good image quality } \\
\text { - More comfortable position } \\
\text { - Easy to transport } \\
\text { - Excellent for training and education of } \\
\text { residents } \\
\text { - Less expensive }\end{array}$ \\
\hline Shirzadi et al. ${ }^{[25]}$ & 2012 & $2 \mathrm{D}$ & $\begin{array}{l}\text { - } 4 \text { lumbar decompressions (1 level) } \\
\text { - } 7 \text { lumbar decompression (2 levels) } \\
\text { - } 11 \text { lumbar TLIF (1 level) } \\
\text { - } 2 \text { lumbar TLIF (2 levels) }\end{array}$ & 24 & $\begin{array}{l}\text { - Lack of stereopsis } \\
\text { - Repositioning the holding arm } \\
\text { - Frequent need for zooming and refocusing }\end{array}$ \\
\hline Parihar et $a l^{[27]}$ & 2016 & $2 \mathrm{D}$ & $\begin{array}{l}\text { - } 4 \text { ACDF } \\
\text { - } 2 \text { ACCF } \\
\text { - } 2 \text { lumbar diskectomies } \\
\text { - } 1 \text { dorsal meningioma } \\
\text { - } 4 \text { neurofibromas (3 dorsal, } 1 \text { cervical) } \\
\text { - } 1 \text { cervical tuberculosis }\end{array}$ & 14 & $\begin{array}{l}\text { - The reduced learning curve of } \\
\text { neuroendoscopy }\end{array}$ \\
\hline Krishnan et al. ${ }^{[35]}$ & 2017 & $2 \mathrm{D}$ & $\begin{array}{l}\text { - } 3 \text { lumbar decompressions } \\
\text { - } 4 \text { lumbar microdiskectomies } \\
\text { - } 2 \text { cervical foraminotomies } \\
\text { - } 1 \text { ACDF procedure }\end{array}$ & 10 & $\begin{array}{l}\text { - Cumbersomeness in repositioning, } \\
\text { refocusing, and varying the magnification. } \\
\text { - Lack of fluorescence filters and navigation } \\
\text { tools }\end{array}$ \\
\hline Oertel et al. ${ }^{[39]}$ & 2017 & $3 D$ & $\begin{array}{l}\text { - } 2 \text { ACDF procedures } \\
\text { - } 1 \text { cervical osteosynthesis } \\
\text { - } 1 \text { lumbar decompression } \\
\text { - } 3 \text { lumbar diskectomies } \\
\text { - } 1 \text { cervical posterior decompression and } \\
\text { fixation } \\
\text { - } 1 \text { TLIF procedure ( } 3 \text { levels) } \\
\text { - } 1 \text { TLIF procedure ( } 1 \text { level) } \\
\text { - } 1 \text { thoracic intraspinal extradural tumor }\end{array}$ & 11 & $\begin{array}{l}\text { - Inferior identification of a bleeding source } \\
\text { as compared to the microscope }\end{array}$ \\
\hline Khalessi et al. ${ }^{[48]}$ & 2019 & $3 D$ & $\begin{array}{l}\text { - } 1 \text { ACDF procedure } \\
\text { - } 2 \text { lumbar posterior decompression }\end{array}$ & 3 & $\begin{array}{l}\text { - During the preliminary testing phase, it is } \\
\text { advisable to have an operating microscope } \\
\text { available in the room }\end{array}$ \\
\hline Beez et al. ${ }^{[43]}$ & 2018 & $3 \mathrm{D}$ & - myelomeningocele closure & 1 & $\begin{array}{l}\text { - The illumination of the OM was considered } \\
\text { superior }\end{array}$ \\
\hline de Divitiis et al. ${ }^{[41]}$ & 2019 & $3 \mathrm{D}$ & $\begin{array}{l}\text { - } 1 \text { intradural hemangioma } \\
\text { - } 2 \text { dorsal Schwannomas } \\
\text { - } 2 \text { dorsal Meningiomas }\end{array}$ & 5 & $\begin{array}{l}\text { - Excellent image quality. } \\
\text { - Need for reposition and refocusing when } \\
\text { surgical exposure changed from extradural } \\
\text { to intradural }\end{array}$ \\
\hline Kwan et al. ${ }^{[47]}$ & 2019 & $3 \mathrm{D}$ & $\begin{array}{l}\text { - } 4 \text { ACDF } \\
\text { - } 1 \text { ACCF } \\
\text { - } 3 \text { cervical laminectomies } \\
\text { - } 2 \text { lumbar laminectomies }\end{array}$ & 10 & $\begin{array}{l}\text { - Wear surgical loupes under 3D glasses; } \\
\text { interchange between loupes and 3D } \\
\text { magnification of the field; use the exoscope } \\
\text { as a sterile, high-intensity flexible light } \\
\text { source }\end{array}$ \\
\hline Barbagallo et al. ${ }^{[44]}$ & 2019 & $3 \mathrm{D}$ & - 2 ACDF-procedures & 2 & $\begin{array}{l}\text { - Indications to the use of the endoscope: } \\
\text { early steps of cervical soft tissue dissection; } \\
\text { for cage insertion, which requires free } \\
\text { maneuverability of the screw and cage } \\
\text { holders under direct vision }\end{array}$ \\
\hline
\end{tabular}

ACDF: anterior cervical decompression and fusion; ACCF: anterior cervical corpectomy and fusion; TLIF: transforaminal lumbar interbody fusion 

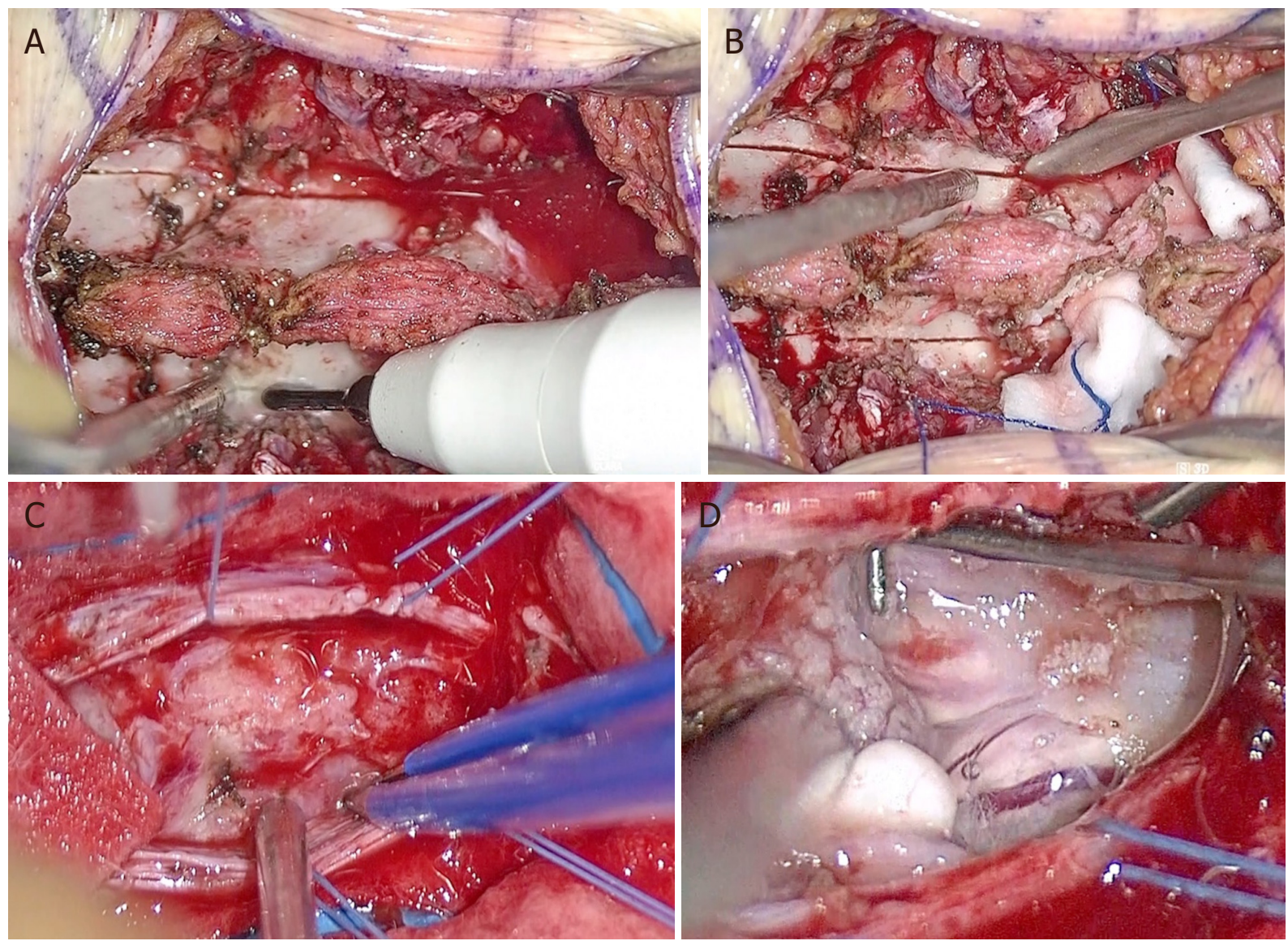

Figure 2. Two levels dorsal laminotomy is performed under visualization of Vitom-3D (A, B); after focus and zoom adjustment, the tumor is exposed and dissected from arachnoidal adherences $(C, D)$ until total removal is achieved

followed by the cervical spine (14\%-27\%), and the lumbar spine (2\%-14\%). At the time of diagnosis, these tumors rarely extend for more than 3 laminae, because of the early occurrence of signs and symptoms of spinal cord compression in their natural history. Considering the above, the optical properties of Vitom-3D, in particular the focal length of 25-60 cm and the large field of view, allow for excellent illumination and magnification of the depth of the surgical field, more in cases of cervical and thoracic meningiomas than lumbar tumors, where the operative field is deeper. Positioning the VITOM camera at the beginning of the surgical approach approximately $35-40 \mathrm{~cm}$ above the operative field, all procedures can be performed with the minimal need for repositioning and refocusing at higher magnifications, due to the quite homogeneous depth of exposure [Figure 2].

In this way, ongoing video documentation step-by-step of the surgical procedure with outstanding quality of the images is available for all the surgical room staff and educational purpose. In cases of meningiomas extending for more than three laminae, exoscope adjustments would likely be more often required. During the extradural steps of the procedure, the surgeon, if wished, could operate under direct vision rather than from the VITOM monitor. Still, it is worth to consider the exoscope a teaching tool of great impact and we suggest its utilization during the whole surgery. Besides, the use of the VITOM from skin incision may help in reducing the learning curve that is associated to the introduction on any new surgical instrument. Fluoroscopy is commonly adopted during meningiomas surgery in order to safely tailor the dimension of the approach to tumor extension. The exoscope doesn't need to be transitioned in and out of the operative field during placement of fluoroscopy, which may contribute to increased efficiency. On the counterpart, the need of two monitors for spinal surgery could reduce the working environment ergonomic. 

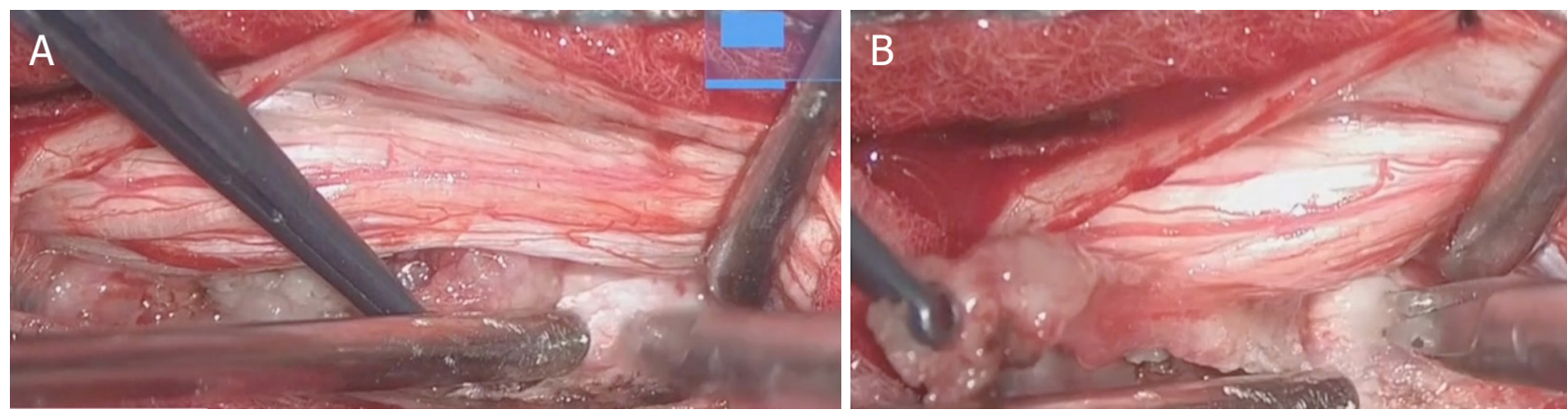

Figure 3. Vitom-3D allows for the identification of spinal meningiomas ventral dural attachment (A); the cleavage plane is followed until complete tumor resection (B)

Oertel et al.$^{[39]}$ reported they experience with only one monitor and the assistance standing right next to the surgeon, both looking at the same screen. However, this is not the usual surgical position and could result inconvenient. Adjustment of the zoom and focus are required at dural opening, when surgical exposure change from the extradural to the intradural space; tumor exposure with the identification of cranial and caudal poles and debulking can be usually performed without the need of further modifications. Zoom should be increased for a safer tumor dissection from the arachnoidal plane and for a better identification of the dural attachment, both in cases of ventral and dorsal meningiomas [Figure 3].

Finally, the large working distance eliminates the conflict between surgical instruments and the exoscope and, when required, allows for the placement of traditional spinal instrumentation.

Meningiomas surgery under exoscope visualization is feasible, safe and efficient. VITOM-3D provides excellent visualization of all relevant structures, including spinal cord, surrounding vessels, spinal roots, tumor-nervous parenchyma interface, and dural attachment. The surgical setting with the camera holding arm on the opposite side of the surgeon, the exoscope at the center of the surgical field without conflicting with his/her dominant hand, and the monitor just in front of the surgeon operating at the side of the patient, allows for maximal comfort of the surgeon that stands upright with arms in a bent and relaxed position during all the surgical steps, and operates from the video monitor. In stands clear that the use of Vitom-3D for meningiomas removal greatly depends on tumor size, consistency, relationship to surrounding neurovascular structures, and surgeon's experience. Switching to the operating microscope, if deemed safer, should always be taken into account.

\section{ILLUSTRATIVE CASE}

A seventeen years old young lady came to our attention because of the acute onset of spinal cord compression syndrome. The neurological examination revealed walking impairment, lower limbs strength deficit, hyperelicitable Achilles and patellar reflexes, positive Romberg sign, urinary incontinence and left hearing loss. Magnetic resonance of the brain and spine showed images suggestive for left acoustic neurinoma, left cavernous sinus meningioma, intradural intramedullary tumor mass at the cranio-cervical junction, and a dorsal intradural-extramedullary meningioma. She underwent genetic screening and neurofibromatosis type 2 was diagnosed. Firstly, the patient underwent surgery for the removal of the medullo-cervical tumor with the assistance of intraoperative neuromonitoring. The surgical procedure was uneventful and the histological diagnosis revealed a low-grade astrocytoma. After complete recovery, the patient was scheduled for the surgical removal of the dorsal tumor. Intraoperative neuromonitoring was used. A skin-to-skin approach under Vitom-3D visualization was performed [Video 1]. Surgery was performed following the common steps of spinal procedures. After a two level D2-D3 laminoplasty, dura was opened and tumor mass was exposed. Macroscopic appearance was consistent with a spinal 
meningioma. The rostral and caudal poles were identified; the tumor was debulked and dissected from the arachnoidal adherences. The dorsal dural attachment was visualized and the tumor was released. En bloc gross total resection was achieved with no intra-operative complications. The exoscope visualization provided excellent images quality, both during the extradural and intradural surgical steps. After initial positioning of the camera $30 \mathrm{~cm}$ above the surgical field, repositioning was never required. Zooming and focusing were adjusted after dural opening; zoom was further increased during tumor dissection. Histological diagnosis confirmed a WHO I spinal meningioma. Clinical and radiological follow-up at three months demonstrated total removal of the meningiomas and walking improvement. Further treatment for the other lesions is planned.

\section{CONCLUSION}

Vitom-3D has recently entered the field of neurosurgery and, in selected case, it represents an alternative visualization tool to the operating microscope. Working environment ergonomics and trainees learning experience are the most relevant benefits associated with the use of exoscope. The optical properties make it best suited for spinal procedures rather than intracranial surgery, both for degenerative diseases and tumors removal. In particular, spinal meningiomas removal under skin-to-skin Vitom-3D visualization only seems feasible, efficient, and safe. Indications to the use of Vitom-3D greatly depend on tumor size, consistency, relationship to surrounding neurovascular structures, and surgeon's experience. Switching to the operating microscope, if deemed safer, should always be considered. Further studies, including larger homogenous series, are needed to better define advantages and limitations of the exoscope in meningiomas surgery as compared to the operating microscope.

\section{DECLARATIONS}

\section{Authors' contributions}

Made substantial contribution to conception of the study: de Divitiis O, Denaro L

Prepared the manuscript draft: d'Avella E, Baro V

Responsible for images and supplementary material: Sacco M, Somma T

Critically revised the final version of the manuscript: de Divitiis O, Turgut M

\section{Availability of data and materials}

Not applicable.

\section{Financial support and sponsorship}

None.

\section{Conflicts of interest}

All authors declared that there are no conflicts of interest.

\section{Ethical approval and consent to participate}

Not applicable.

\section{Consent for publication}

Not Applicable.

\section{Copyright}

(c) The Author(s) 2020. 


\section{REFERENCES}

1. Joaquim AF, Almeida JP, Dos Santos MJ, et al. Surgical management of intradural extramedullary tumors located anteriorly to the spinal cord. J Clin Neurosci 2012;19:1150-3.

2. Maiuri F, De Caro ML, de Divitiis O, Vergara P, Mariniello G. Spinal meningiomas: age-related features. Clin Neurol Neurosurg 2011;113:34-8.

3. Saraceni C, Harrop JS. Spinal meningioma: chronicles of contemporary neurosurgical diagnosis and management. Clin Neurol Neurosurg 2009;111:221-6.

4. Klekamp J, Samii M. Surgery of Spinal Tumors. Berlin, Heidelberg: Springer; 2007.

5. Voldřich R, Netuka D, Beneš V. Spinal meningiomas: is Simpson grade II resection radical enough? Acta Neurochir (Wien) 2020;162:1401-8.

6. Setzer M, Vatter H, Marquardt G, Seifert V, Vrionis FD. Management of spinal meningiomas: surgical results and a review of the literature. Neurosurg Focus 2007;23:E14.

7. Hohenberger C, Gugg C, Schmidt NO, Zeman F, Schebesch KM. Functional outcome after surgical treatment of spinal meningioma. J Clin Neurosci 2020:11:62-6.

8. Dhandapani S, Karthigeyan M. "Microendoscopic" versus "pure endoscopic" surgery for spinal intradural mass lesions: a comparative study and review. Spine J 2018;18:1592-602.

9. Parihar VS, Yadav N, Yadav YR, et al. Endoscopic management of spinal intradural extramedullary tumors. J Neurol Surg A Cent Eur Neurosurg 2017;78:219-26.

10. Lakomkin N, Mistry AM, Zuckerman SL, et al. Utility of Intraoperative Monitoring in the Resection of Spinal Cord Tumors: An Analysis by Tumor Location and Anatomical Region. Spine (Phila Pa 1976) 2018;43:287-94.

11. Yasargil MG, Krayenbuhl H. The use of the binocular microscope in neurosurgery. Bibl Ophthalmol 1970;81:62-5.

12. Caspar W. A new surgical procedure for lumbar disc herniation causing less tissue damage through a microsurgical approach. In: Wüllenweber R, Brock M, Hamer J, Klinger M, Spoerri O, editors. Lumbar Disc Adult Hydrocephalus. Berlin, Heidelberg: Springer; 1977.

13. Yasargil MG. Microneurosurgery: in 4 volumes. New York: Thieme Stratton; 1984.

14. Kriss TC, Kriss VM. History of the operating microscope: from magnifying glass to microneurosurgery. Neurosurgery 1998;42:899-907; discussion 907-8.

15. Uluc K, Kujoth GC, Baskaya MK. Operating microscopes: past, present, and future. Neurosurg Focus 2009;27:E4.

16. Yasargil MG, Vise WM, Bader DC. Technical adjuncts in neurosurgery. Surg Neurol 1977;8:331-6.

17. Cavallo LM, Di Somma A, Solari D, et al. Preliminary experience with a new multidirectional videoendoscope for neuroendoscopic surgical procedures. PLoS One 2016;11:e0147524.

18. Cinalli G, Cappabianca P, de Falco R, et al. Current state and future development of intracranial neuroendoscopic surgery. Expert Rev Med Devices 2005;2:351-73.

19. Esposito F, Cappabianca P. Neuroendoscopy: general aspects and principles. World Neurosurg 2013;79:S14.e7-9.

20. Zada G, Liu C, Apuzzo ML. "Through the looking glass": optical physics, issues, and the evolution of neuroendoscopy. World Neurosurg 2013;79:S3-13.

21. Cavallo LM, Somma T, Solari D, et al. Endoscopic endonasal transsphenoidal surgery: history and evolution. World Neurosurg 2019;127:686-94.

22. Mamelak AN, Danielpour M, Black KL, Hagike M, Berci G. A high-definition exoscope system for neurosurgery and other microsurgical disciplines: preliminary report. Surg Innov 2008;15:38-46.

23. Mamelak AN, Nobuto T, Berci G. Initial clinical experience with a high-definition exoscope system for microneurosurgery. Neurosurgery 2010;67:476-83.

24. Mamelak AN, Drazin D, Shirzadi A, Black KL, Berci G. Infratentorial supracerebellar resection of a pineal tumor using a high definition video exoscope (VITOM(R)). J Clin Neurosci 2012;19:306-9.

25. Shirzadi A, Mukherjee D, Drazin DG, et al. Use of the video telescope operating monitor (VITOM) as an alternative to the operating microscope in spine surgery. Spine (Phila Pa 1976) 2012;37:E1517-23.

26. Piquer J, Llacer JL, Rovira V, et al. Fluorescence-guided surgery and biopsy in gliomas with an exoscope system. Biomed Res Int 2014;2014:207974.

27. Parihar V, Yadav YR, Kher Y, et al. Learning neuroendoscopy with an exoscope system (video telescopic operating monitor): Early clinical results. Asian J Neurosurg 2016;11:421-6.

28. Fischer G, Oertel J, Perneczky A. Endoscopy in aneurysm surgery. Neurosurgery 2012;70:184-90; discussion 90-1.

29. Carlucci C, Fasanella L, Ricci Maccarini A. Exolaryngoscopy: a new technique for laryngeal surgery. Acta Otorhinolaryngol Ital 2012;32:326-8.

30. Divers SJ. Video telescope operating microscopy. Vet Clin North Am Exot Anim Pract 2015;18:571-8.

31. Frykman PK, Freedman AL, Kane TD, et al. A study of VITOM in pediatric surgery and urology: evaluation of technology acceptance and usability by operating team and surgeon musculoskeletal discomfort. J Laparoendosc Adv Surg Tech A 2017;27:191-6.

32. Vercellino GF, Erdemoglu E, Kyeyamwa S, et al. Evaluation of the VITOM in digital high-definition video exocolposcopy. J Low Genit Tract Dis 2011;15:292-5.

33. Marzano E, Piardi T, Soler L, et al. Augmented reality-guided artery-first pancreatico-duodenectomy. J Gastrointest Surg 2013;17:19803. 
34. Moisi M, Tubbs RS, Page J, et al. Training medical novices in spinal microsurgery: does the modality matter? A pilot study comparing traditional microscopic surgery and a novel robotic optoelectronic visualization tool. Cureus 2016;8:e469.

35. Krishnan KG, Scholler K, Uhl E. Application of a compact high-definition exoscope for illumination and magnification in high-precision surgical procedures. World Neurosurg 2017;97:652-60.

36. Birch K, Drazin D, Black KL, et al. Clinical experience with a high definition exoscope system for surgery of pineal region lesions. $J$ Clin Neurosci 2014;21:1245-9.

37. Nagatani K, Takeuchi S, Feng D, Mori K, Day JD. High-definition exoscope system for microneurosurgery: use of an exoscope in combination with tubular retraction and frameless neuronavigation for microsurgical resection of deep brain lesions. No Shinkei Geka 2015;43:611-7.

38. Belloch JP, Rovira V, Llacer JL, Riesgo PA, Cremades A. Fluorescence-guided surgery in high grade gliomas using an exoscope system. Acta Neurochir (Wien) 2014;156:653-60.

39. Oertel JM, Burkhardt BW. Vitom-3D for exoscopic neurosurgery: initial experience in cranial and spinal procedures. World Neurosurg 2017; 105:153-62.

40. Rossini Z, Cardia A, Milani D, et al. VITOM 3D: preliminary experience in cranial surgery. World Neurosurg 2017;107:663-8.

41. de Divitiis O, D'avella E, Denaro L, et al. Vitom 3D: preliminary experience with intradural extramedullary spinal tumors. J Neurosurg Sci 2019; doi: 10.23736/S0390-5616.19.04666-6.

42. Angileri FF, Esposito F, Scibilia A, et al. Exoscope-guided (VITOM 3D) single-stage removal of supratentorial cavernous angioma and hemangioblastoma: 3-dimensional operative video. Oper Neurosurg (Hagerstown) 2019;17:E164-5.

43. Beez T, Munoz-Bendix C, Beseoglu K, Steiger HJ, Ahmadi SA. First clinical applications of a high-definition three-dimensional exoscope in pediatric neurosurgery. Cureus 2018;10:e2108.

44. Barbagallo GMV, Certo F. Three-dimensional, high-definition exoscopic anterior cervical discectomy and fusion: a valid alternative to microscope-assisted surgery. World Neurosurg 2019;130:e244-50.

45. De Virgilio A, Costantino A, Ebm C, et al. High definition three-dimensional exoscope (VITOM 3D) for microsurgery training: a preliminary experience. Eur Arch Otorhinolaryngol 2020;277:2589-95.

46. Nossek E, Schneider JR, Kwan K, et al. Technical aspects and operative nuances using a high-definition 3-dimensional exoscope for cerebral bypass surgery. Oper Neurosurg (Hagerstown) 2019;17:157-63.

47. Kwan K, Schneider JR, Du V, et al. Lessons learned using a high-definition 3-dimensional exoscope for spinal surgery. Oper Neurosurg (Hagerstown) 2019;16:619-25.

48. Khalessi AA, Rahme R, Rennert RC, et al. First-in-man clinical experience using a high-definition 3-dimensional exoscope system for microneurosurgery. Oper Neurosurg (Hagerstown) 2019;16:717-25.

49. Sack J, Steinberg JA, Rennert RC, et al. Initial experience using a high-definition 3-dimensional exoscope system for microneurosurgery. Oper Neurosurg (Hagerstown) 2018;14:395-401.

50. de Divitiis O, Somma T, Sacco M, d'Avella E, Guizzardi G. VITOM ${ }^{\circledR}-3 \mathrm{D}$ in lumbar disc herniation: preliminary experience. Interdiscip Neurosurg 2019;18:100547.

51. Herlan S, Marquardt JS, Hirt B, Tatagiba M, Ebner FH. 3D exoscope system in neurosurgery-comparison of a standard operating microscope with a new 3D exoscope in the cadaver lab. Oper Neurosurg (Hagerstown) 2019;17:518-24.

52. Garneau JC, Laitman BM, Cosetti MK, Hadjipanayis C, Wanna G. The use of the exoscope in lateral skull base surgery: advantages and limitations. Otol Neurotol 2019;40:236-40.

53. Doglietto F, Belotti F, Panciani P, Poliani PL, Fontanella MM. High-definition 3-dimensional exoscope for 5-ALA glioma surgery: 3-dimensional operative video. Oper Neurosurg (Hagerstown) 2020;18:E82.

54. Hafez A, Elsharkawy A, Schwartz C, et al. Comparison of conventional microscopic and exoscopic experimental bypass anastomosis: a technical analysis. World Neurosurg 2020;135:e293-9.

55. Langer DJ, White TG, Schulder M, Boockvar JA, Labib M, et al. Advances in intraoperative optics: a brief review of current exoscope platforms. Oper Neurosurg (Hagerstown) 2020;19:84-93. 